\title{
A Novel Dual-Band Circularly Polarized Rectangular Slot Antenna
}

\author{
Biao Li, ${ }^{1}$ Yang Ding, ${ }^{2}$ and Ying-Zeng Yin $^{3}$ \\ ${ }^{1}$ CAST-Xian Institute of Space Radio Technology, Xian, Shaanxi 710100, China \\ ${ }^{2}$ AVIC-Xian Flight Automatic Control Research Institute, Xian, Shaanxi 710065, China \\ ${ }^{3}$ National Laboratory of Antennas and Microwave Technology, Xidian University, Xian, Shaanxi 710071, China \\ Correspondence should be addressed to Biao Li; libiao504@163.com
}

Received 21 November 2015; Revised 9 March 2016; Accepted 7 April 2016

Academic Editor: Renato Cicchetti

Copyright (c) 2016 Biao Li et al. This is an open access article distributed under the Creative Commons Attribution License, which permits unrestricted use, distribution, and reproduction in any medium, provided the original work is properly cited.

A coplanar waveguide fed dual-band circularly polarized rectangular slot antenna is presented. The proposed antenna consists of a rectangular metal frame acting as a ground and an S-shaped monopole as a radiator. The spatial distribution of the surface current density is employed to demonstrate that the circular polarization is generated by the S-shaped monopole which controls the path of the surface currents. An antenna prototype, having overall dimension $37 \times 37 \times 1 \mathrm{~mm}^{3}$, has been fabricated on FR4 substrate with dielectric constant 4.4. The proposed antenna achieves $10 \mathrm{~dB}$ return loss bandwidths and $3 \mathrm{~dB}$ axial ratio (AR) in the frequency bands $2.39-2.81 \mathrm{GHz}$ and 5.42-5.92 GHz, respectively. Both these characteristics are suitable for WLAN and WiMAX applications.

\section{Introduction}

The rapid development in wireless communications with different standards has resulted in a huge demand for multiband antennas. Coplanar waveguide (CPW) fed slot antennas exhibit attractive features for multiband applications because of its favorable characteristics, such as wide bandwidth, light weight, low profile, less sensitivity to manufacturing tolerances, and easy integration with microwave integrated circuits. Circular polarization (CP) antennas have attracted much attention in the design of wireless systems since they are more effective in receiving and transmitting signals having arbitrary directions and polarizations. In addition, they can limit the multipath effect caused by walls and ground surfaces [1]. Moreover, the circular polarization provides better mobility and a field propagation less sensible to weather condition. Both these characteristics may prove useful in WLAN and WiMAX applications.

Several single-fed dual bands design solutions for the excitation of the circular polarization have been recently proposed in the literature [2-11]. Some of these solutions consist in the realization of an asymmetrical four-arm structure [7] or in spiral slots integrated in the ground plane [8]. A CPW-fed circular fractal slot antenna for dual-band applications has been presented in [9]. However, only few designs of coplanar waveguide single-fed dual-frequency slot antennas for circular polarization have been reported in literature [9-11]. In any case, all the mentioned antennas have a complex structure. In this paper, a novel design of a CPWfed CP antenna with dual-band operation is introduced. The proposed antenna is formed by a rectangular metallic frame, acting as ground plane, inside which an S-shaped monopole is placed. The S-shaped monopole changes the path of the currents making the antenna more compact and suitable to excite a dual-band CP operation. The field vector composition, based on the surface current distribution flowing on the monopole and on the metal frame, is employed to explain the excitation of the dual-band CP operation. The antenna can find applications in wireless communication systems such as wireless routers and wireless access points. Details concerning the antenna design and experimental results are presented and discussed.

\section{Antenna Configuration and Analysis}

2.1. Configuration of the Proposed Antenna. Figure 1 shows the geometry and the photograph of the realized antenna. 

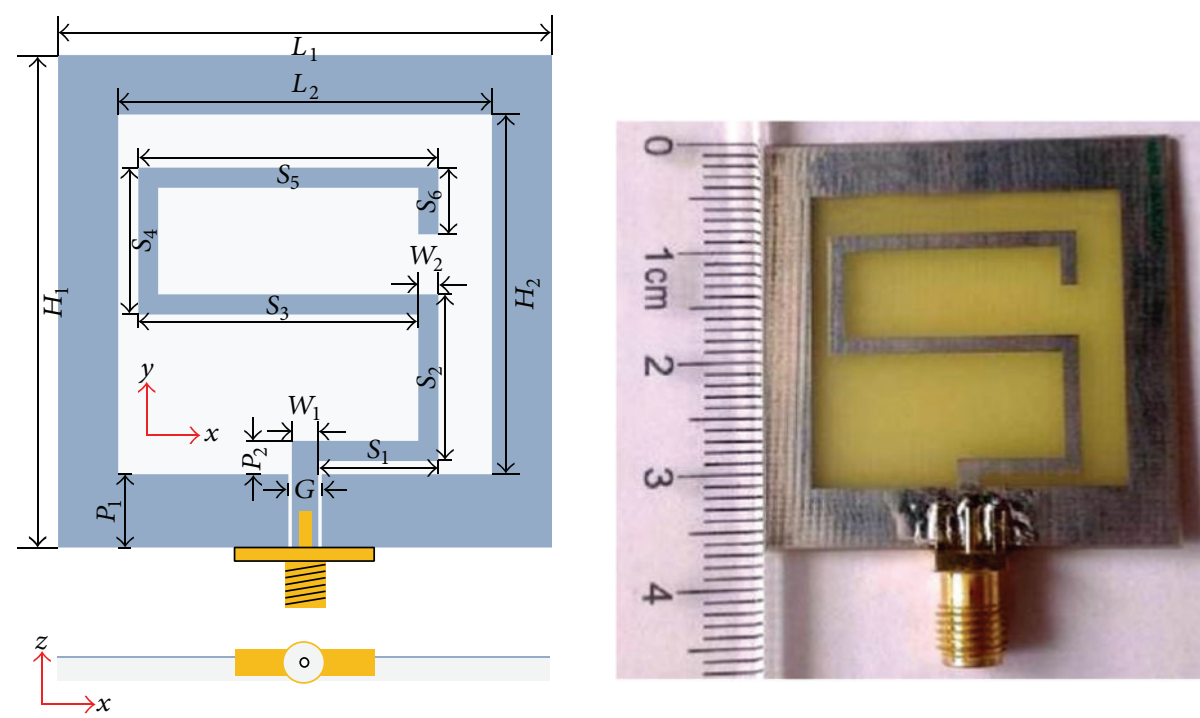

FIGURE 1: Geometry and photograph of the proposed antenna.

The antenna is printed on a low cost FR4 substrate having thickness $1 \mathrm{~mm}$, dielectric constant 4.4, and loss tangent 0.02 . The area of the antenna is $L_{1} \times H_{1} . L_{2}$ and $H_{2}$ are the width and height of the rectangle slot. The S-shaped monopole, composed of 6 straight metal sections of width $W_{2}$ and the lengths of $S_{1}, S_{2}, S_{3}, S_{4}, S_{5}$, and $S_{6}$, respectively, is fed by the coplanar waveguide. The CPW, designed for a $50 \Omega$ characteristic impedance, consists of a stripline having width equal to $2 \mathrm{~mm}$ and a gap of $0.25 \mathrm{~mm}$, respectively. The feed line is terminated with a standard SMA connector.

The full-wave commercial software Ansys HFSS has been adopted to determine the antenna performances. After completing the optimizing process the following antenna parameters were derived: $L_{1}=37 \mathrm{~mm}, H_{1}=37 \mathrm{~mm}, L_{2}=$ $28 \mathrm{~mm}, H_{2}=27 \mathrm{~mm}, P_{1}=5.5 \mathrm{~mm}, P_{2}=2.5 \mathrm{~mm}, G=2.5 \mathrm{~mm}$, $W_{1}=2 \mathrm{~mm}, W_{2}=1.5 \mathrm{~mm}, S_{1}=9 \mathrm{~mm}, S_{2}=12.5 \mathrm{~mm}, S_{3}=$ $21 \mathrm{~mm}, S_{4}=11 \mathrm{~mm}, S_{5}=22.5 \mathrm{~mm}$, and $S_{6}=5 \mathrm{~mm}$. With these parameters an antenna with an impedance band in the frequency ranges $2.27-2.81 \mathrm{GHz}$ and $4.94-6.08 \mathrm{GHz}$ and with an axial ratio below $3 \mathrm{~dB}$ in the $2.39-2.98 \mathrm{GHz}$ and $5.42-$ $5.92 \mathrm{GHz}$ frequency bands, respectively, is obtained. These features ensure the coverage of the frequency bands WLAN and WiMAX.

2.2. Antenna Evolution and Dual-Band Operation. Figure 2 illustrates the topological changes necessary to modify a straight monopole (Antenna Type I) into a more compact antenna having the desired dual-band characteristic (Antenna Type III), while Figure 3(a) shows the related $S_{11}$ parameters.

In general, the length of monopole antenna is usually about a quarter-wavelength. Notice that the fundamental resonance frequency of Antenna Type I is of about $2.5 \mathrm{GHz}$, while the high-order resonant modes are employed to excite the circular polarization in the proposed S-shaped monopole

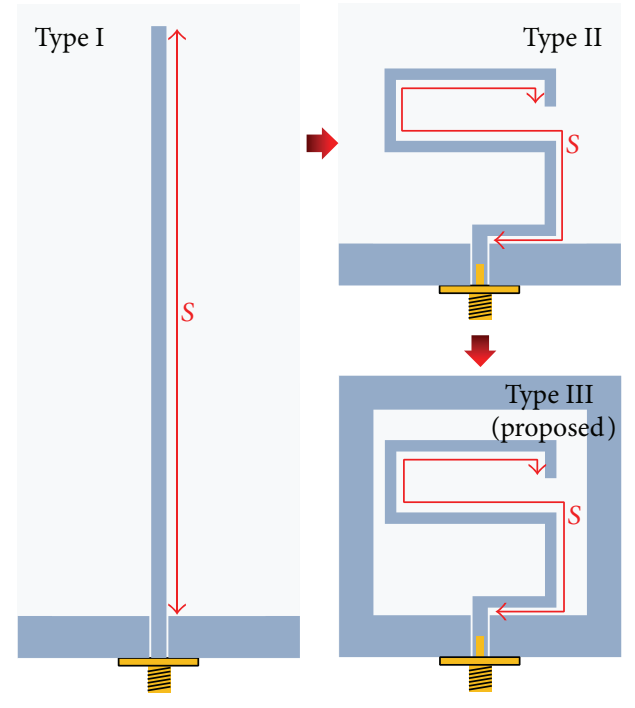

FIGURE 2: The evolution of the proposed antenna.

antenna (see Figures 8 and 9). When the antenna is operating at its resonant frequency, the imaginary part of its impedance becomes about zero. The simulated results of the input resistance and reactance of the three types of the antenna are shown in Figures 4(a) and 4(b). The surface currents of Antenna Type I have many null points due to the high-order modes, which will cause a deterioration of the radiation pattern. The current distribution along the Sshaped monopole (Antenna Types II and III) is different from that flowing on the straight monopole (Antenna Type I), exciting in this way a circularly polarized field whose AR, along the positive $z$-direction for Antenna Types II and III, are reported in Figure 3(b). By analyzing Figure 3 it can be observed that Antenna Type III is the one that presents the 


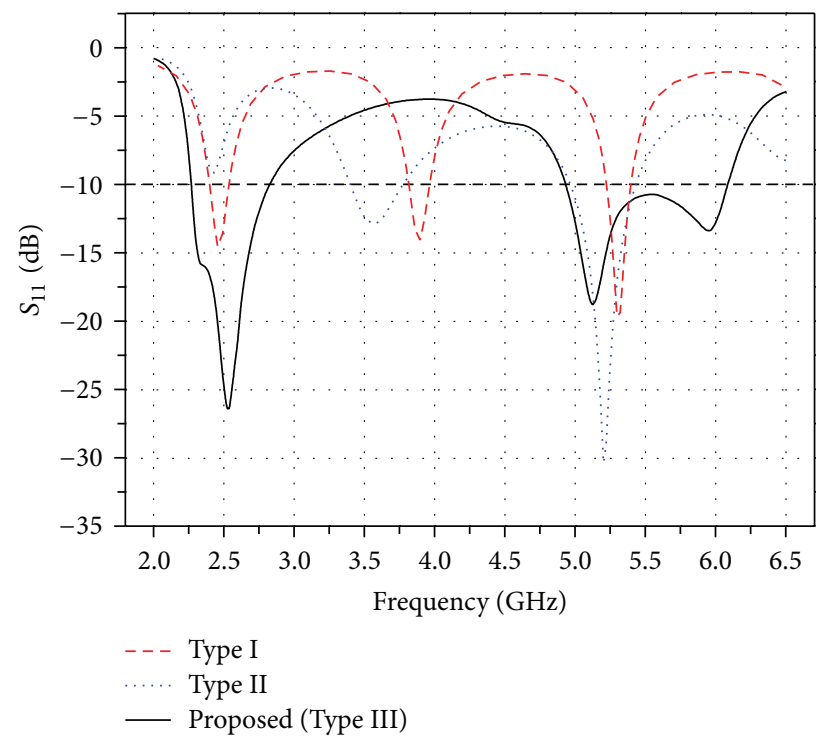

(a)

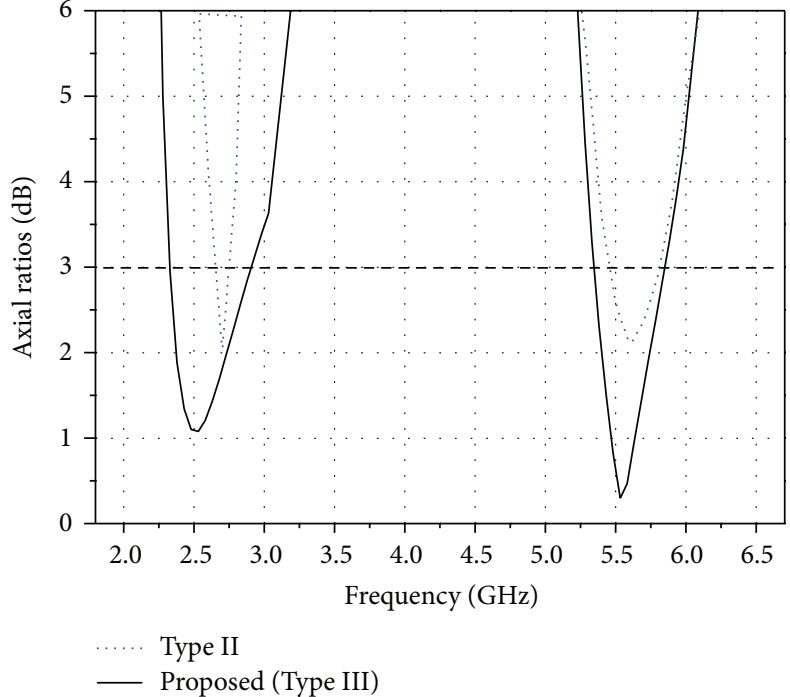

(b)

Figure 3: (a) The simulated $S_{11}$ of Antenna Type I and Type II and the proposed antenna (Type III). (b) The simulated axial ratio of Antenna Type II and the proposed antenna (Type III).

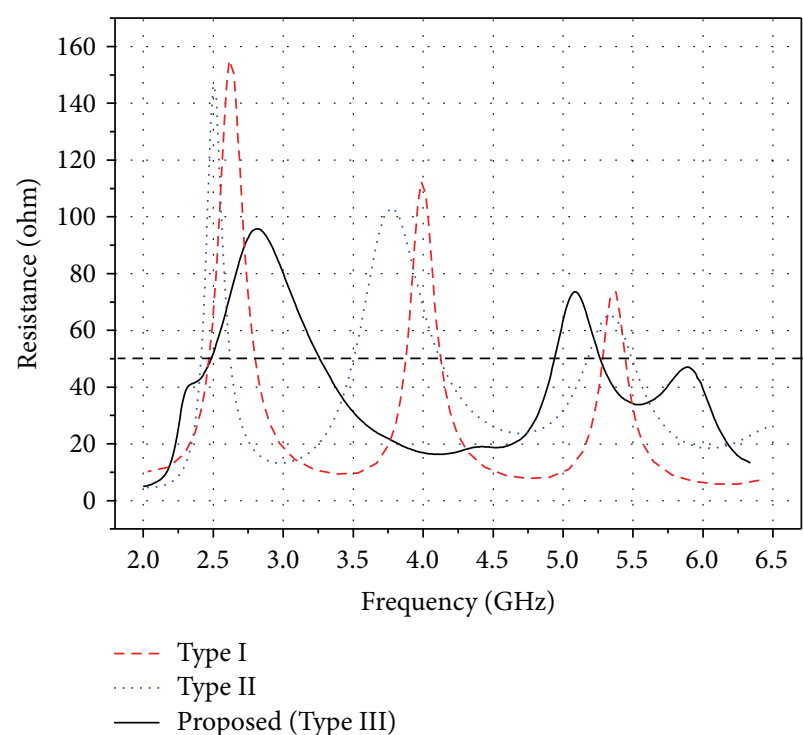

(a)

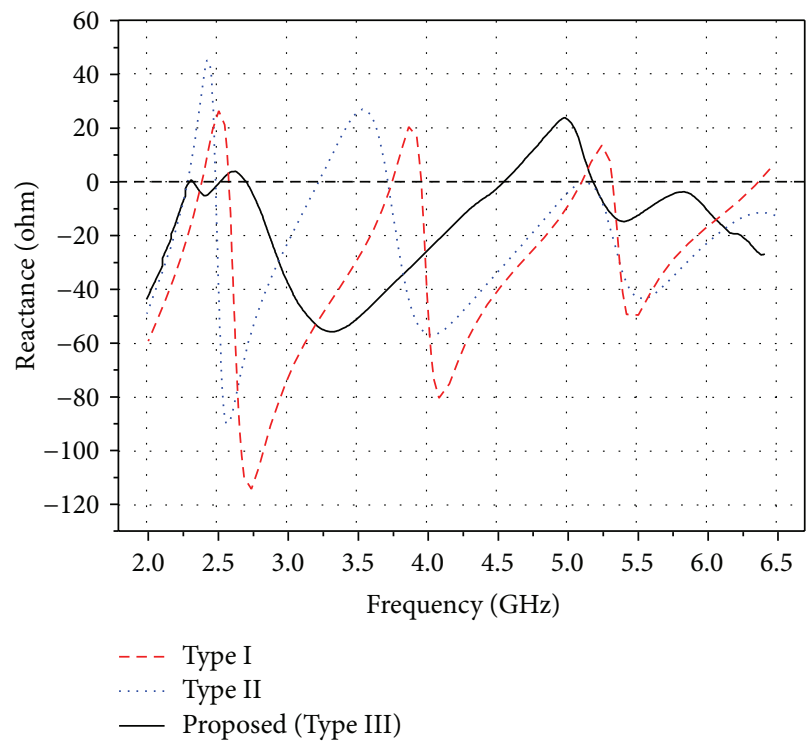

(b)

FIGURE 4: The simulated input (a) resistance and (b) reactance of Antenna Type I and Type II and the proposed antenna (Type III).

best performance and consequently is the one that has been realized. The excitation of the circular polarization and the effect of the ground parameters on the antenna performance will be discussed in the next sections.

2.3. Parametric Study. In order to investigate the effects of various parameters on the antenna performance, an extensive parametric analysis has been performed. To this purpose each antenna parameter was changed keeping the others to a constant value. Unless specified, the fixed parameters were chosen so to coincide with those of the optimized design.

The length of each stub $S_{i}(i=1 \sim 6)$ of the S-shaped monopole is the key parameter of the antenna performance. As an illustration, the frequency behavior of the $S_{11}$ parameters and that of the axial ratio computed along the positive $z$-direction, for different lengths of the parameters $S_{4}$ and $S_{5}$, are shown in Figure 5. $S_{4}+S_{5}$ is set to be a constant according to the evolution of Type I to Type II. There is no obvious frequency shift of $S_{11}$, but impedance matching is 


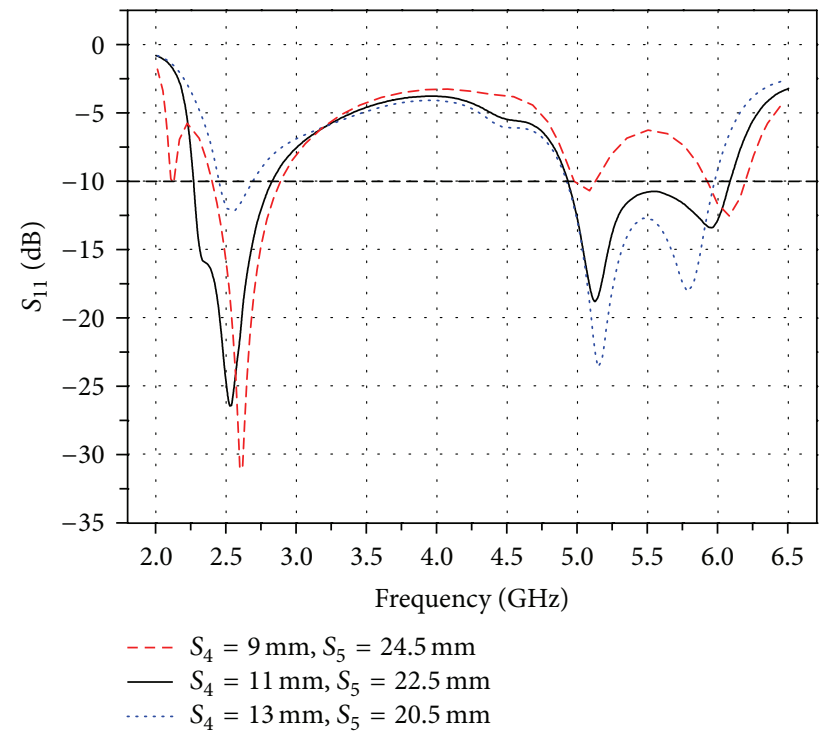

(a)

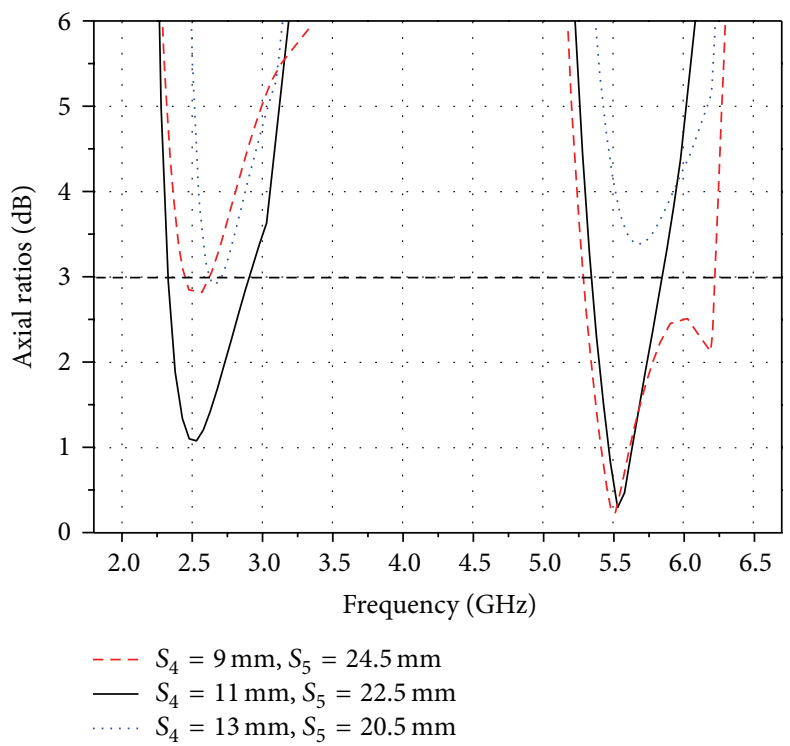

(b)

FIgURE 5: The simulated (a) $S_{11}$ and (b) axial ratio for different $S_{4}$ and $S_{5}$ values of the proposed antenna (Type III).

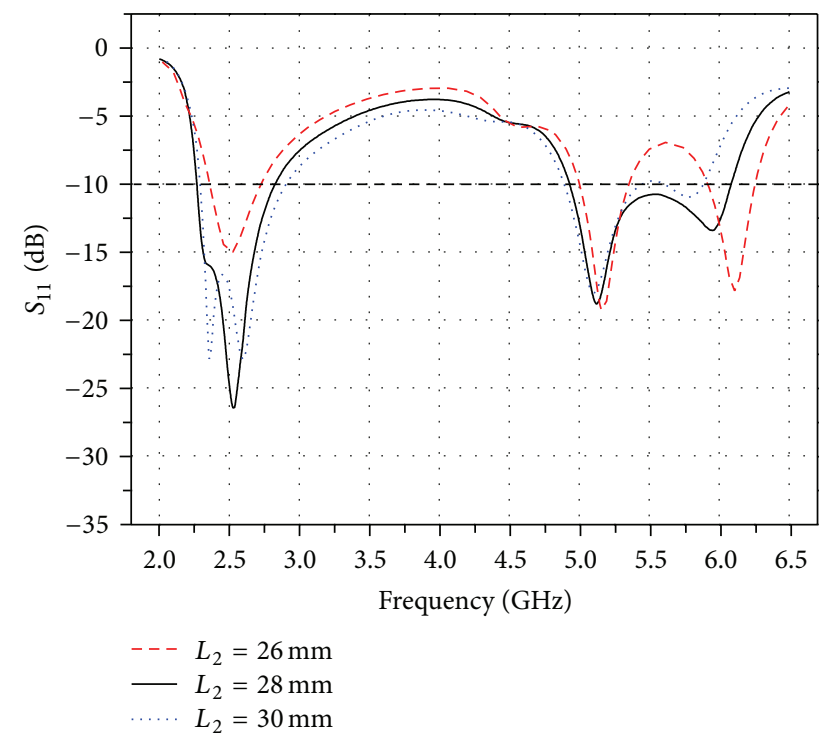

(a)

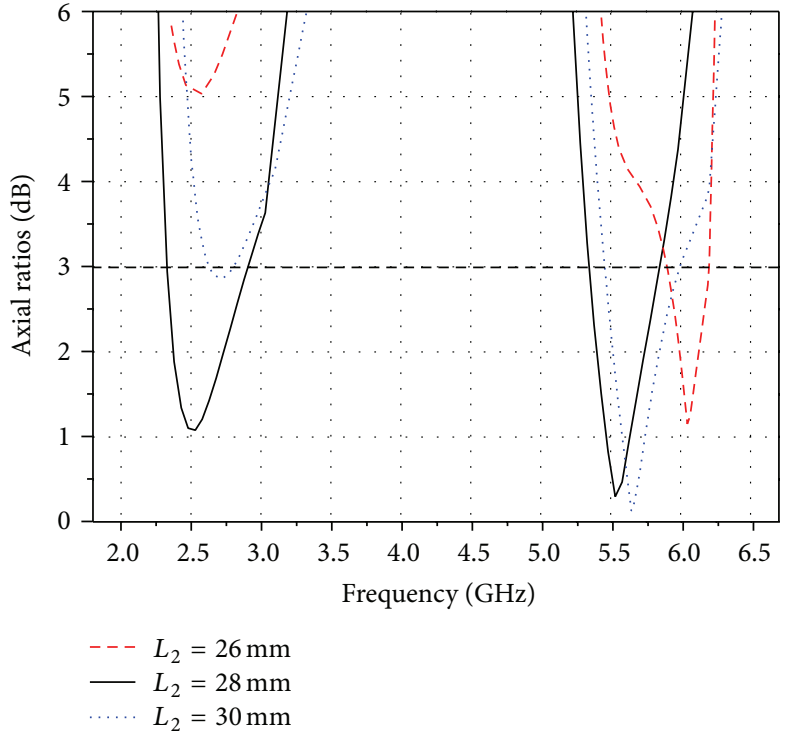

(b)

FIgURE 6: The simulated (a) $S_{11}$ and (b) axial ratio for different $L_{2}$ values of the proposed antenna (Type III).

deteriorated at the lower band and improved at the upper band as the length $S_{5}$ decreases. $S_{4}=11 \mathrm{~mm}$ and $S_{5}=22.5 \mathrm{~mm}$ are the optimum design for the AR.

As mentioned above, the parameters of the rectangular slot $\left(L_{2}, H_{2}\right)$, which can be seen as a ground extension of Antenna Type II, can affect the impedance and AR bandwidth of the antenna. A parametric analysis is performed to evaluate the influence of these parameters on antenna characteristics. Figures 6 and 7 show the frequency behavior of the $S_{11}$ parameters and AR along the positive $z$-direction for different values of the antenna geometrical parameters
$L_{2}$ and $H_{2}$. It can be seen that $L_{2}$ and $H_{2}$, which affect the impedance matching of the antenna, have a great effect on $A R$ at the lower frequency but less effect at the upper frequency. According to these simulation results $L_{2}=28 \mathrm{~mm}$ and $H_{2}=$ $27 \mathrm{~mm}$ are chosen as the optimal value.

2.4. Circular Polarization Analysis. To excite the circular polarization, the antenna must radiate fields of equal magnitude that are orthogonal in space and in time. In order to illustrate how the circular polarization is achieved, the simulated surface currents distributions at $2.5 \mathrm{GHz}$ and $5.75 \mathrm{GHz}$, 


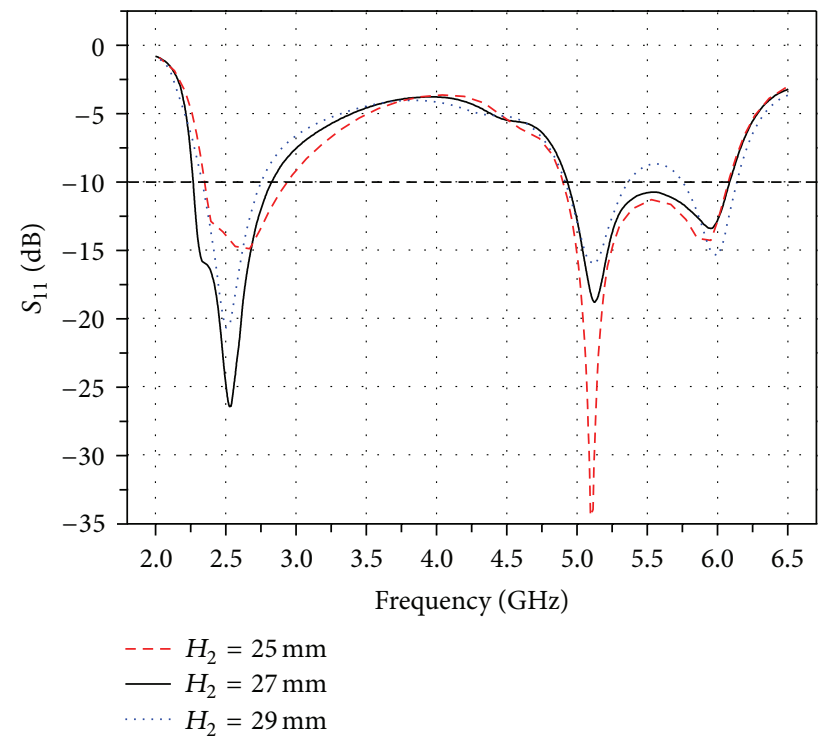

(a)

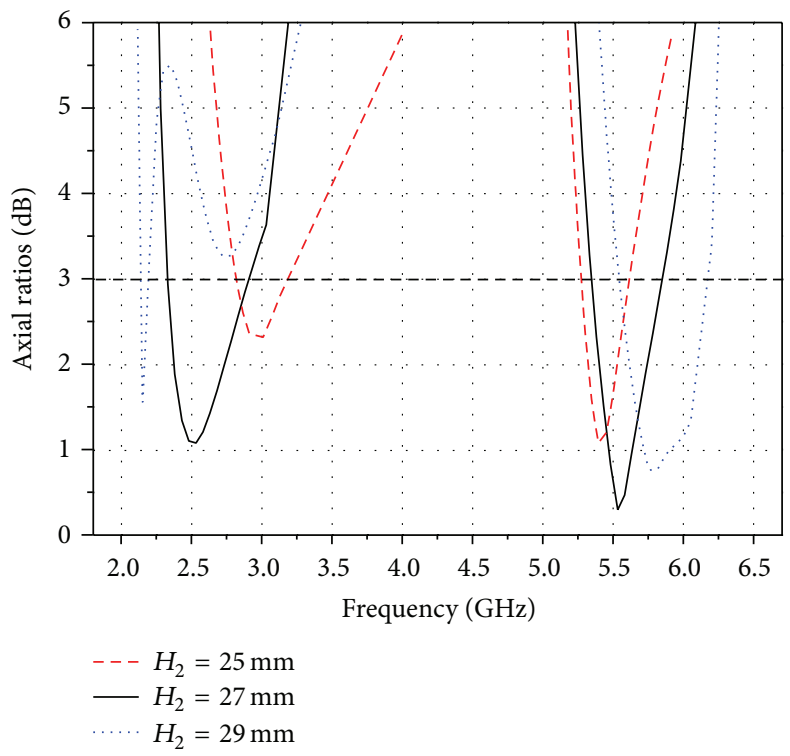

(b)

FIgURE 7: The simulated (a) $S_{11}$ and (b) axial ratio for different $H_{2}$ values of the proposed antenna (Type III).

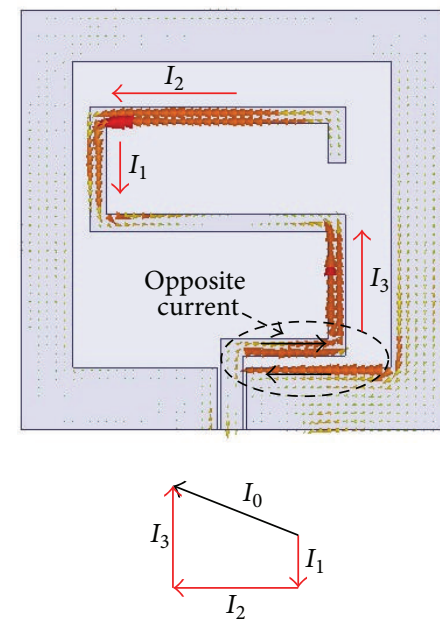

(a)
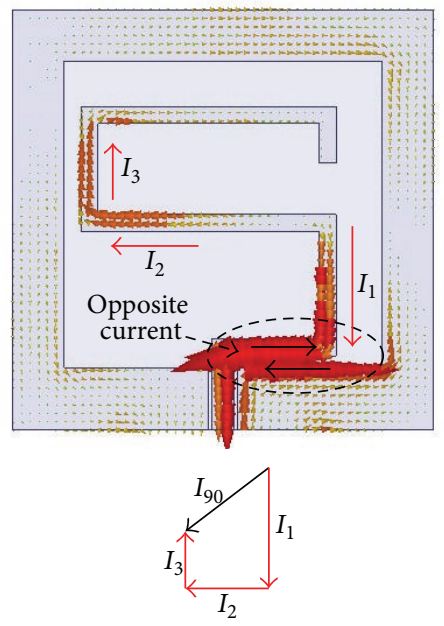

(b)

Figure 8: Simulated surface currents distributions at orthogonal phases (a) $0^{\circ}$ and (b) $90^{\circ}$ at $2.5 \mathrm{GHz}$ of the proposed antenna.

when the phase of the exciting signal is $0^{\circ}$ and $90^{\circ}$, are shown in Figures 8 and 9, respectively. The analysis based on the current vector composition employed in [11] is adopted to identify the polarization state of the radiated field. However, since the adjacent surface currents with the same intensity and opposite directions do not provide contribution to the far field, they are not taken into account. From the analysis of Figures 8 and 9 it is clear that the dominant radiating vectors on the antenna surface excite a right-hand polarized field along the positive $z$-direction at the considered frequencies of $2.5 \mathrm{GHz}$ and $5.75 \mathrm{GHz}$.

\section{Results and Discussion}

An antenna prototype has been realized to verify the performances of the proposed antenna. The antenna has been analyzed using a full-wave commercial software (Ansys HFSS 15). The measures of the scattering parameters have been carried out by using a WILTRON37269A vector network analyzer, while those concerning the radiation patterns have been derived by means of a fully automated anechoic chamber.

The measured and simulated $S$-parameters results are depicted in Figure 10. The antenna presents a simulated 

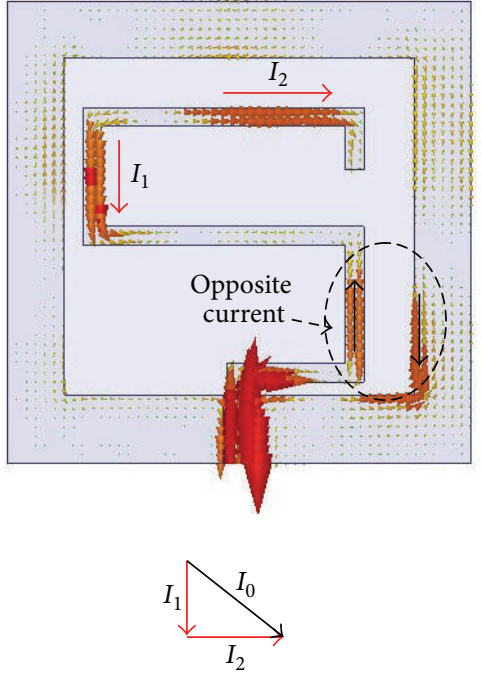

(a)
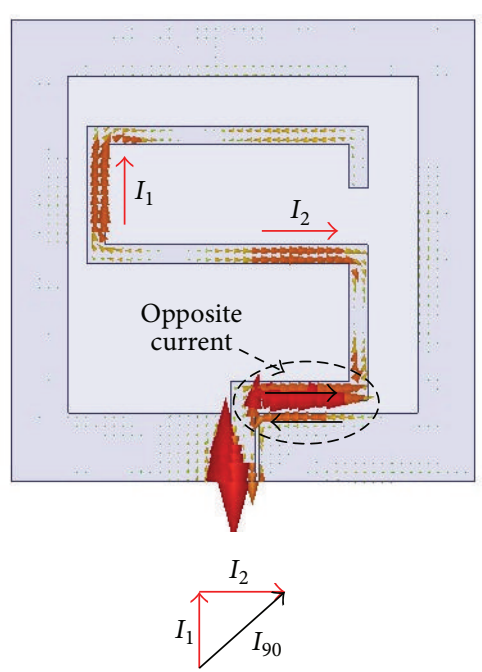

(b)

FIgURE 9: Simulated surface currents distributions at orthogonal phases (a) $0^{\circ}$ and (b) $90^{\circ}$ at $5.75 \mathrm{GHz}$ of the proposed antenna.

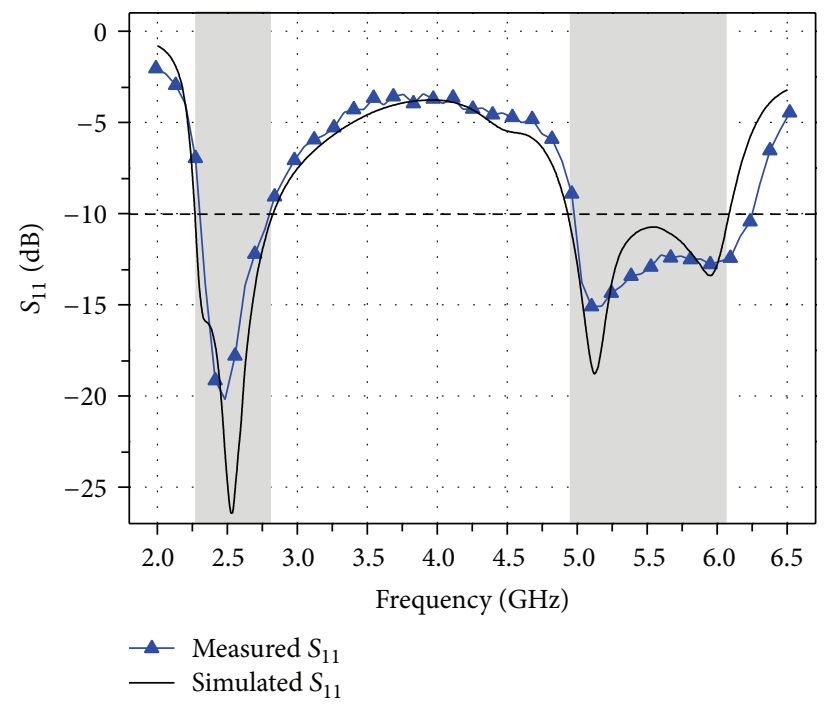

Figure 10: Measured and simulated $S_{11}$ of the proposed antenna.

bandwidth $\left(S_{11} \leq-10 \mathrm{~dB}\right)$ of $21.3 \%(2.27-2.81 \mathrm{GHz})$ and $20.7 \%(4.94-6.08 \mathrm{GHz})$ and a measured bandwidth of $18.5 \%$ $(2.31-2.78 \mathrm{GHz})$ and $22.6 \%(4.99-6.26 \mathrm{GHz})$ in the first and second operative band, respectively. The simulated and measured values of the axial ratio $(\mathrm{AR}<3 \mathrm{~dB})$ in the direction of maximum radiation (along the $z$-axis direction) are shown in Figure 11. From Figure 11 it appears that the proposed antenna exhibits excellent circular polarization. In particular, simulated axial ratio bandwidths of $21.9 \%$ (2.39$2.98 \mathrm{GHz})$ and $8.8 \%(5.42-5.92 \mathrm{GHz})$ and measured axial ratio bandwidths of $19.6 \%(2.30-2.80 \mathrm{GHz})$ and $8.8 \%(5.40-$ $5.90 \mathrm{GHz}$ ) are observed in the figure. Finally, it can be observed that the numerical results concerning the operative bands of the proposed antenna are in good agreement with

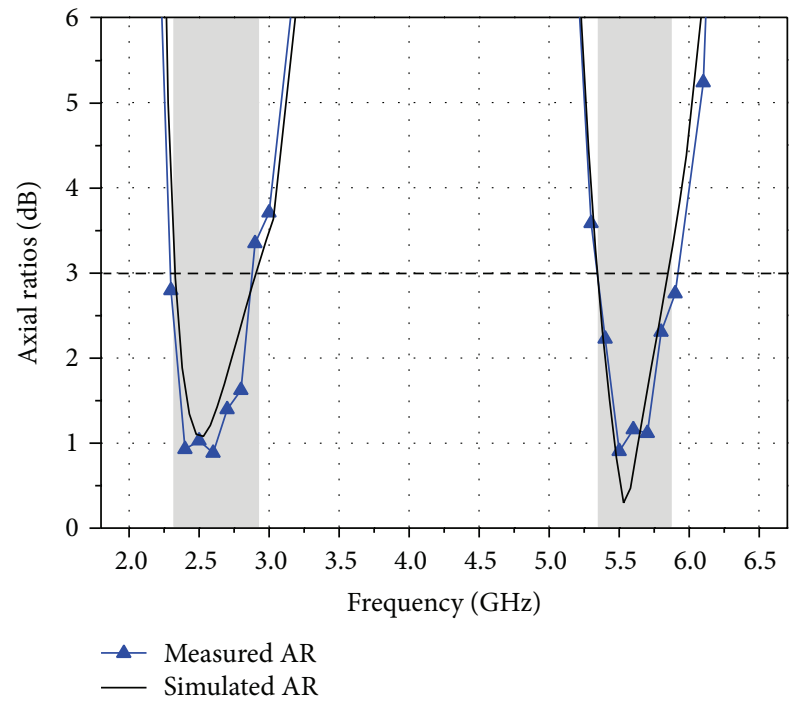

FIGURE 11: Measured and simulated axial ratio of the proposed antenna.

the experimental measurements. Therefore, the operative bands of the antenna, that is, those where both the impedance and axial ratio requirements are satisfied simultaneously, are between 2.39 and $2.81 \mathrm{GHz}$ and between 5.42 and $5.92 \mathrm{GHz}$, respectively.

Figure 12 shows the measured and simulated radiation pattern for $X Z$-plane and $Y Z$-plane at $2.5 \mathrm{GHz}$ and $5.75 \mathrm{GHz}$, respectively. From Figure 12 it appears that the proposed antenna radiates right-hand circular polarization (RHCP) in the positive $z$-direction and left-hand circular polarization (LHCP) in the negative $z$-direction. The level of the cross polarization along the main beam direction is lower than 


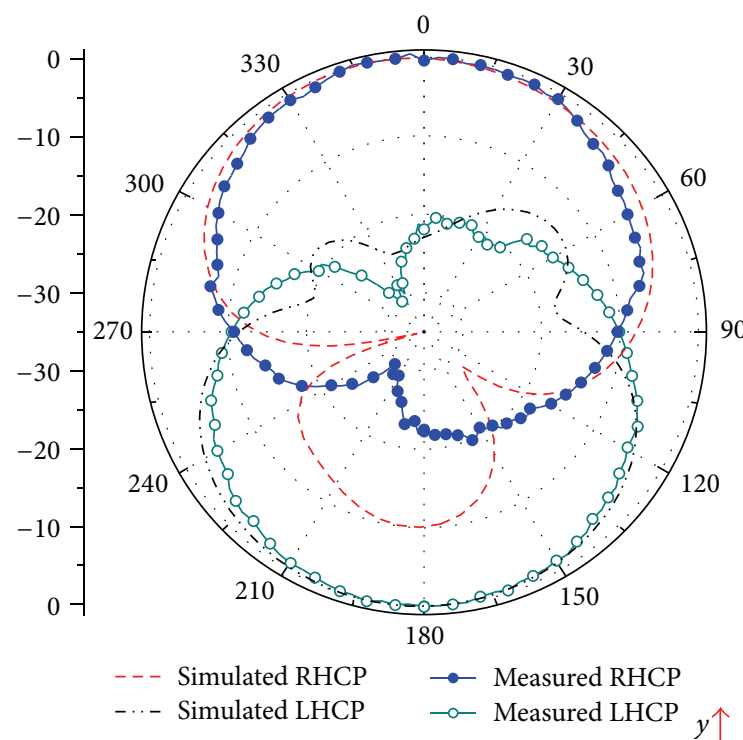

(a)

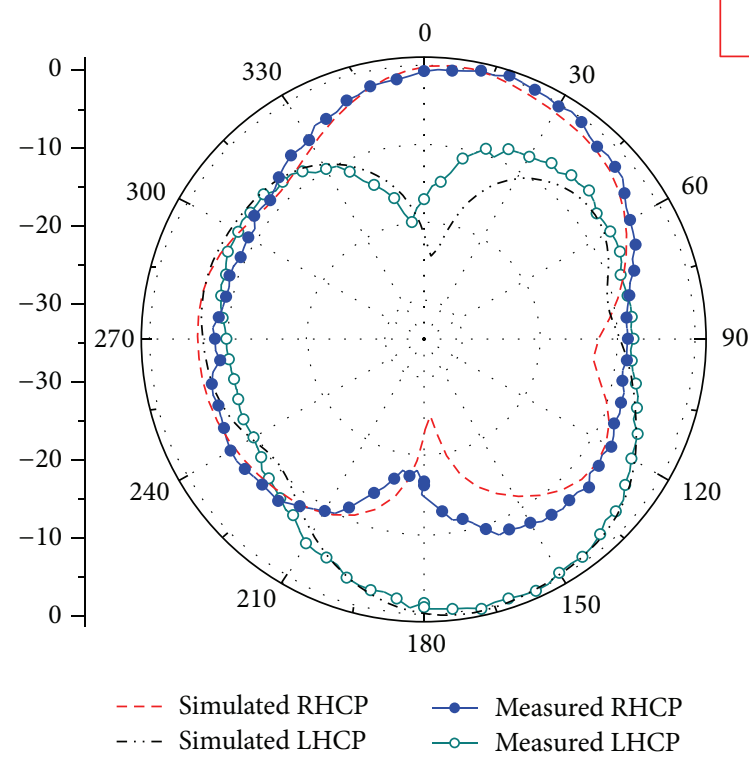

(c)

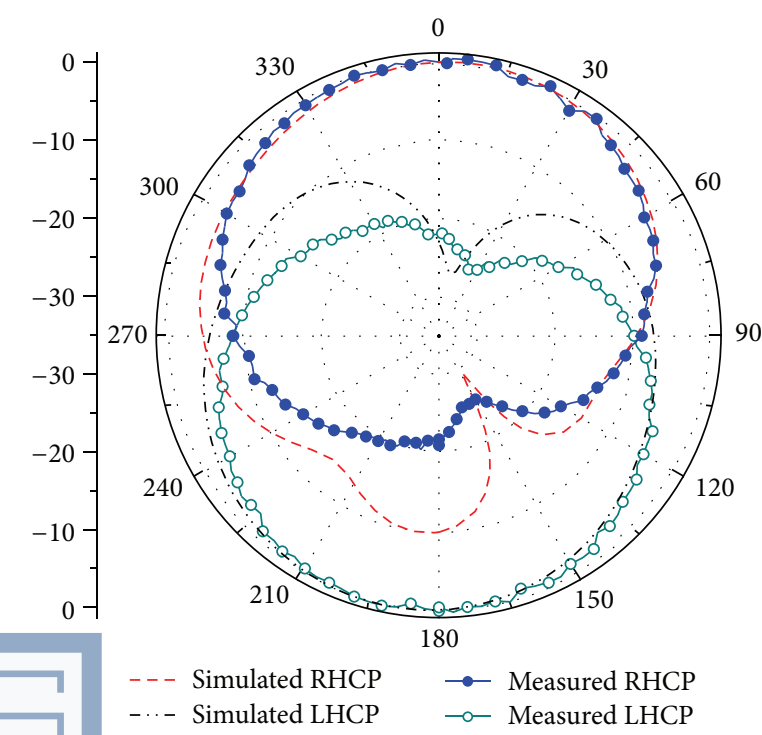

(b)

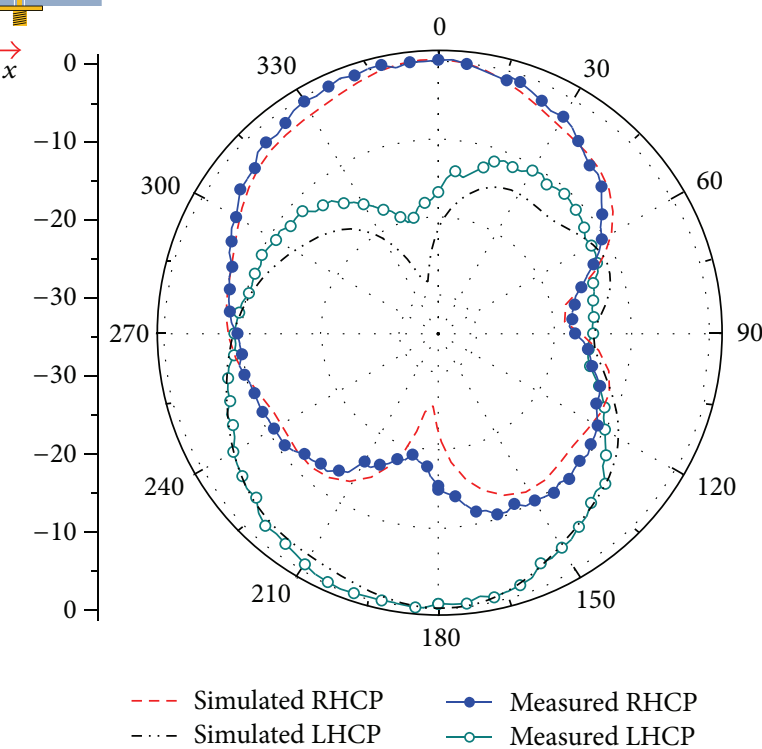

(d)

Figure 12: Measured and simulated radiation pattern of the proposed antenna. (a) XZ-plane at 2.5 GHz, (b) $Y Z$-plane at 2.5 GHz, (c) XZplane at $5.75 \mathrm{GHz}$, and (d) $Y Z$-plane at $5.75 \mathrm{GHz}$.

$15 \mathrm{~dB}$ and $8 \mathrm{~dB}$ in the lower band and the higher band, respectively.

The gain of the proposed antenna is measured by using the comparison method. To this end the gain measurement was performed combining the vertical and horizontal field levels measured using a linearly polarized Standard Gain Antenna. Antenna gains of about $3.3 \mathrm{dBi}$, in the lower band, and of about $3.8 \mathrm{dBi}$, in the higher band, are observed along the $z$-direction (see Figure 13). The radiation efficiency using wheeler cap method [12] is also incorporated in Figure 13, which shows an average efficiency of $80 \%$ and $83 \%$ in the first and second bands, respectively.

\section{Conclusion}

A novel dual-band circularly polarized CPW-fed rectangular slot antenna has been presented. The vector composition of the surface current distribution has been employed to demonstrate that the S-shaped monopole is suitable to control the currents path so to excite the circular polarization. Finally, the experimental measurements performed on a prototype have shown that the proposed antenna achieves a $10 \mathrm{~dB}$ return loss in the frequency bands $2.31-2.78 \mathrm{GHz}$ and 4.99-6.26 GHz, respectively, while it exhibits a $3 \mathrm{~dB}$ axial ratio in the frequency bands $2.30-2.80 \mathrm{GHz}$ and $5.40-5.90 \mathrm{GHz}$. 


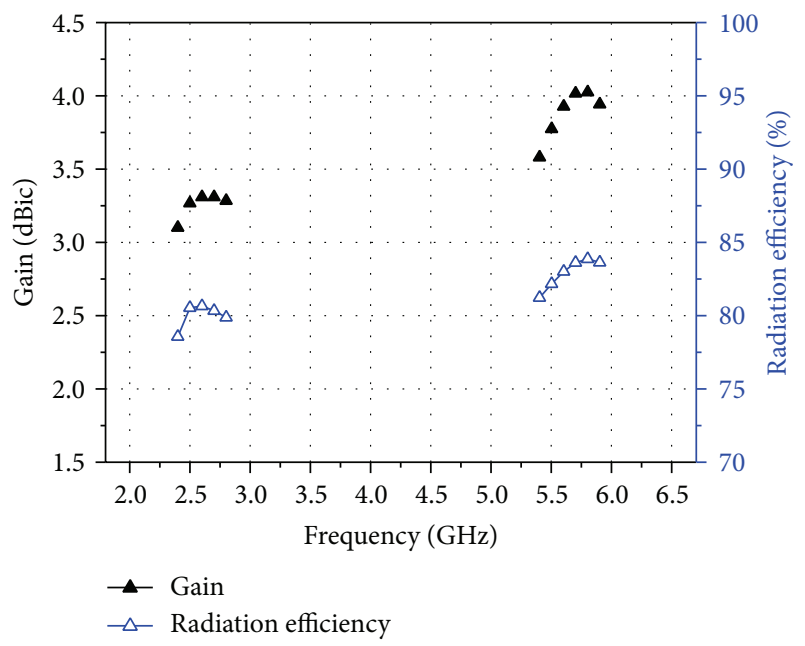

Figure 13: Measured gain and radiation efficiency of the proposed antenna.

Therefore, it appears as a good candidate for communications requiring circular polarizations in the WLAN and WiMAX frequency bands.

\section{Competing Interests}

The authors declare that they have no competing interests.

\section{References}

[1] P. Bernardi, R. Cicchetti, and O. Testa, "An accurate UTD model for the analysis of complex indoor radio environments in microwave WLAN systems," IEEE Transactions on Antennas and Propagation, vol. 52, no. 6, pp. 1509-1520, 2004.

[2] J. Yang, C.-H. Liang, and T. Wang, "Novel dual-band circularly polarized wideband antenna for WLAN and WiMAX," Journal of Electromagnetic Waves and Applications, vol. 26, no. 14-15, pp. 1881-1888, 2012.

[3] P. Nayeri, K.-F. Lee, A. Z. Elsherbeni, and F. Yang, "Dualband circularly polarized antennas using stacked patches with asymmetric U-slots," IEEE Antennas and Wireless Propagation Letters, vol. 10, pp. 492-495, 2011.

[4] A. A. Heidari, M. Heyrani, and M. Nakhkash, "A dual-band circularly polarized stub loaded microstrip patch antenna for GPS applications," Progress in Electromagnetics Research, vol. 92, pp. 195-208, 2009.

[5] M. Samsuzzaman, M. T. Islam, H. Arshad, J. S. Mandeep, and N. Misran, "Circularly polarized S band dual frequency square patch antenna using glass microfiber reinforced PTFE composite," The Scientific World Journal, vol. 2014, Article ID 345190, 10 pages, 2014.

[6] T. S. Ooi, S. K. A. Rahim, and B. P. Koh, " $2.45 \mathrm{GHz}$ and $5.8 \mathrm{GHz}$ compact dual-band circularly polarized patch antenna," Journal of Electromagnetic Waves and Applications, vol. 24, no. 11-12, pp. 1473-1482, 2010.

[7] S. X. Ta and I. Park, "Dual-band operation of a circularly polarized four-arm curl antenna with asymmetric arm length," International Journal of Antennas and Propagation, vol. 2016, Article ID 3531089, 10 pages, 2016.
[8] X. L. Bao and M. J. Ammann, "Monofilar spiral slot antenna for dual-frequency dual-sense circular polarization," IEEE Transactions on Antennas and Propagation, vol. 59, no. 8, pp. 3061-3065, 2011.

[9] D.-C. Chang, B.-H. Zeng, and J.-C. Liu, "CPW-fed circular fractal slot antenna design for dual-band applications," IEEE Transactions on Antennas and Propagation, vol. 56, no. 12, pp. 3630-3636, 2008.

[10] C. H. Chen and E. K. N. Yung, "Dual-band dual-sense circularly-polarized CPW-fed slot antenna with two spiral slots loaded," IEEE Transactions on Antennas and Propagation, vol. 57, no. 6, pp. 1829-1833, 2009.

[11] C.-H. Chen and E. K. N. Yung, "Dual-band circularly-polarized CPW-fed slot antenna with a small frequency ratio and wide bandwidths," IEEE Transactions on Antennas and Propagation, vol. 59, no. 4, pp. 1379-1384, 2011.

[12] D. M. Pozar and B. Kaufman, "Comparison of three methods for the measurement of printed antenna efficiency," IEEE Transactions on Antennas and Propagation, vol. 36, no. 1, pp. 136-139, 1988. 


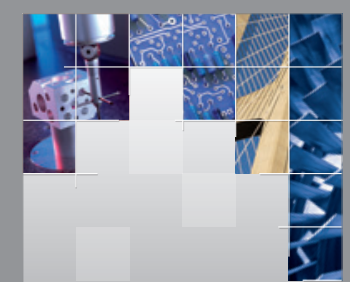

\section{Enfincering}
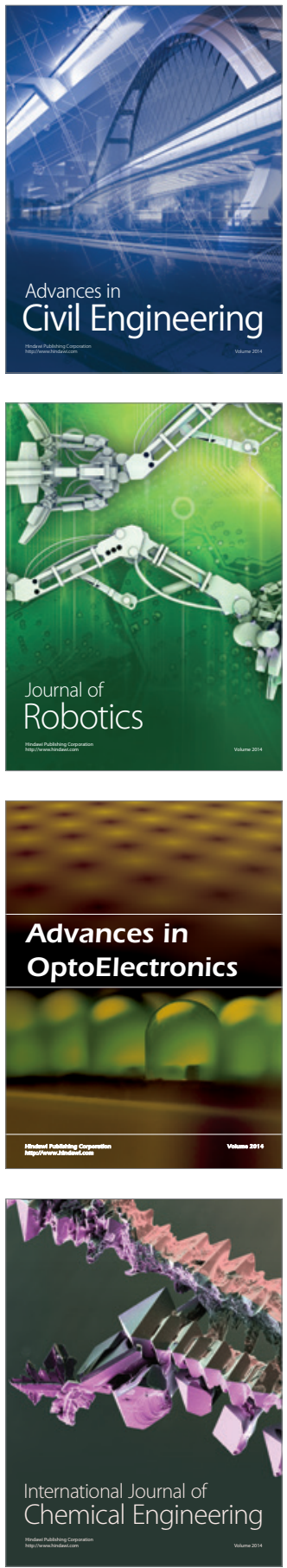

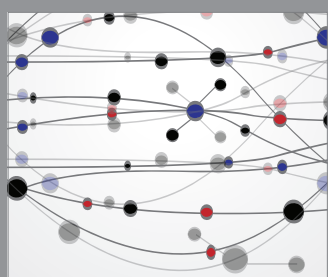

The Scientific World Journal

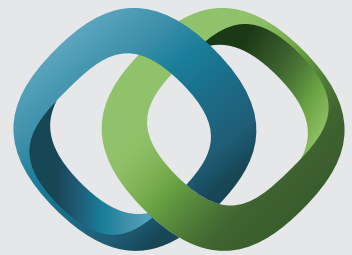

\section{Hindawi}

Submit your manuscripts at

http://www.hindawi.com
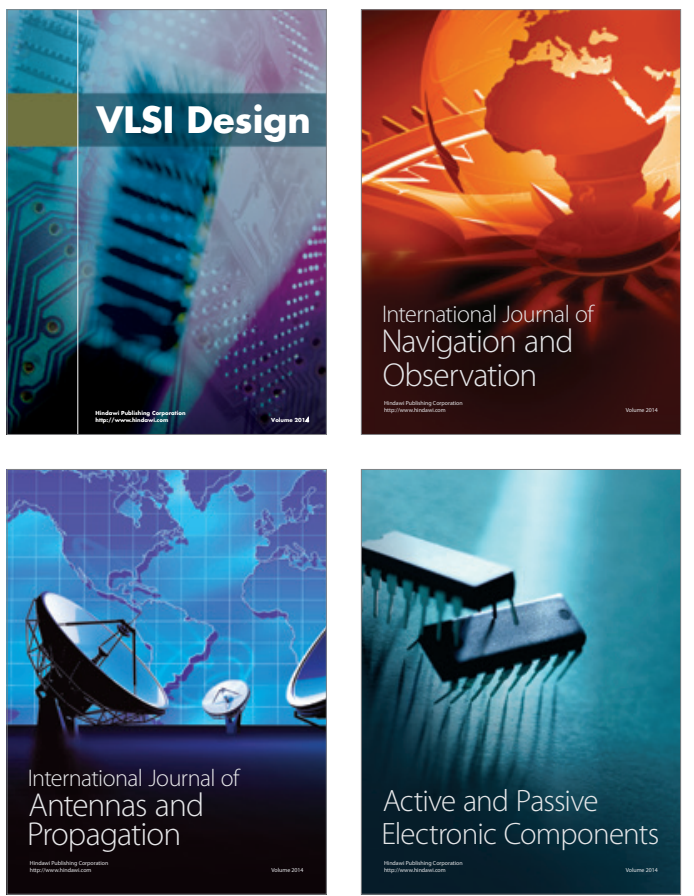
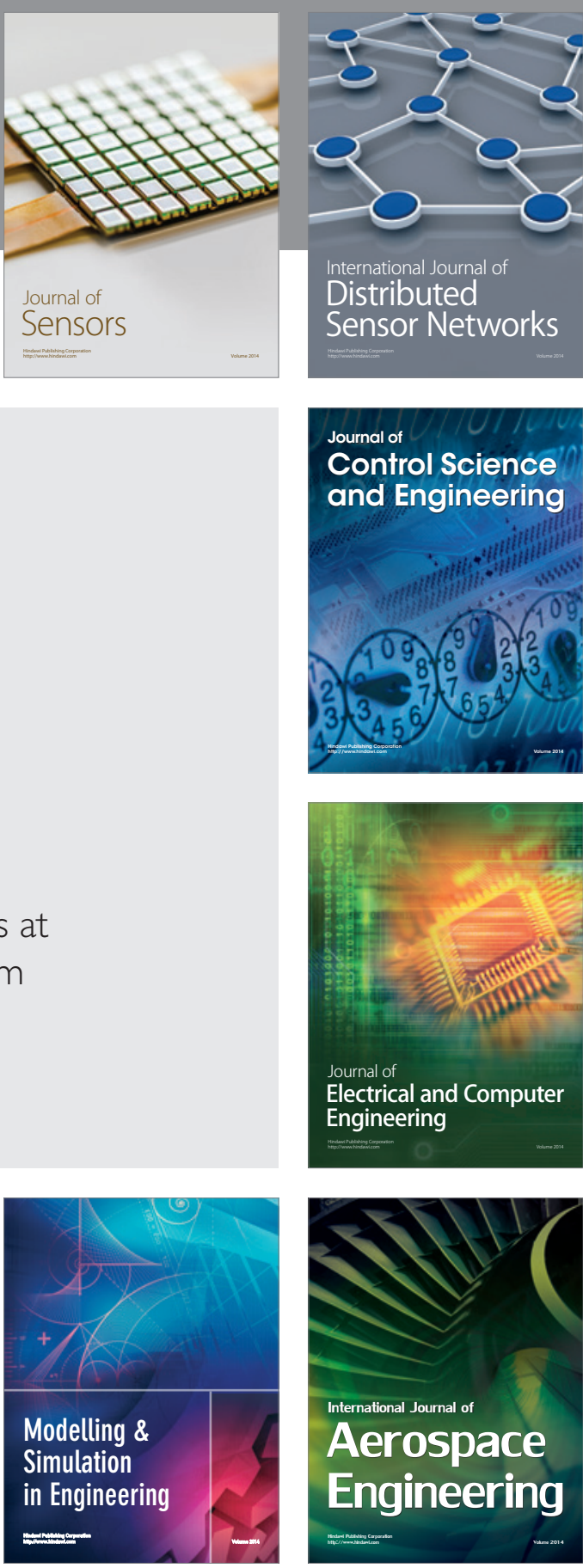

International Journal of

Distributed

Sensor Networks

Journal of

Control Science

and Engineering
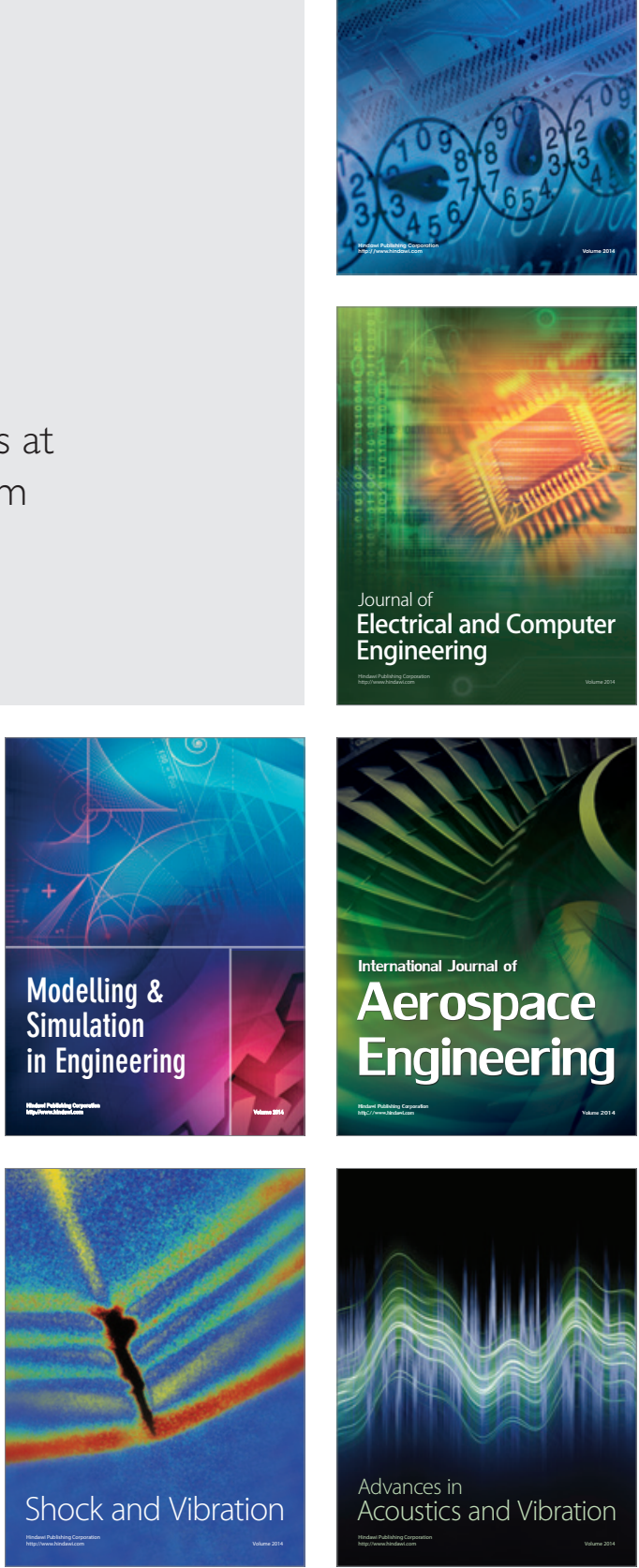